\title{
Water Vapor Transport and Moisture Budget over Eastern China: Remote Forcing from the Two Types of El Niño
}

\author{
XIUZHEN LI AND WEN ZHOU \\ Guy Carpenter Asia-Pacific Climate Impact Centre, School of Energy and Environment, City University of Hong Kong, \\ Hong Kong, and City University of Hong Kong Shenzhen Research Institute, Shenzhen, China

\section{Deliang CHEN} \\ Department of Earth Science, University of Gothenburg, Gothenburg, Sweden \\ CHONGYIN Li AND JIE SONG \\ LASG, Institute of Atmospheric Physics, Chinese Academy of Sciences, Beijing, China
}

(Manuscript received 9 January 2014, in final form 22 August 2014)

\begin{abstract}
The water vapor transport and moisture budget over eastern China remotely forced by the cold-tongue (CT) and warm-pool (WP) El Niño show striking differences throughout their lifetime. The water vapor transport response is weak in the developing summer but strong in the remaining phases of CT El Niño, whereas the opposite occurs during WP El Niño. WP El Niño causes a moisture deficit over the Yangtze River valley (YZ) in the developing summer and over southeastern China (SE) in the developing fall, whereas CT El Niño induces a moisture surplus first over SE during the developing fall with the influential area expanding in the decaying spring and shifting northward in the decaying summer. It is the divergence of meridional water vapor transport that dominates the total water vapor divergence anomaly, with the divergence of zonal transport showing an opposite pattern with smaller magnitude.

Investigation of the vertical profile of moisture budget shows a great baroclinicity, with the strongest abnormal moisture budget occurring in different levels. The moisture transport via the southern boundary plays a crucial role in the regional moisture budget anomalies and is located near the surface over SE, in the lower troposphere over the YZ, and at the lower-middle troposphere over the eastern part of northern China. The enhanced moisture surplus near the surface forced by WP El Niño over SE in the mature winter and decaying spring is offset by a moisture deficit within the lower-middle troposphere due to a diverse response circulation at different vertical levels.
\end{abstract}

\section{Introduction}

The El Niño-Southern Oscillation (ENSO) phenomenon, an energetic interannual fluctuation over the tropical Pacific, has a remarkable influence on the climate variation over East Asia (e.g., Huang and Wu 1989; Zhang et al. 1996; Chan and Zhou 2005; Zhou et al. 2006; Li et al. 2006; Wang et al. 2006, 2011; Zhou and Chan 2007; Gu et al. 2009; Feng et al. 2010, 2011; Chen et al. 2012). During different phases, sea surface temperature

\footnotetext{
Corresponding author address: Dr. Wen Zhou, School of Energy and Environment, City University of Hong Kong, Tat Chee Avenue, Kowloon, Hong Kong, China.

E-mail:wenzhou@cityu.edu.hk
}

anomalies (SSTAs) over the tropical Pacific have different impacts on the atmospheric circulation and thus the rainfall pattern over East Asia (Yang et al. 2004; Wang et al. 2009).

In recent decades, besides the conventional El Niño [cold-tongue (CT) El Niño], a new type of El Niño [warm-pool (WP) El Niño] has been a subject of increasing interest (Kug et al. 2009). WP El Niño, also known as the date line El Niño (Larkin and Harrison 2005), El Niño Modoki (Ashok et al. 2007; Weng et al. 2009), or central Pacific El Niño (Kao and Yu 2009), describes an anomalously warm equatorial central Pacific flanked by anomalously cool regions to both its west and east. It has become frequent during the past two decades and may become even more common in 
a warming climate (Yeh et al. 2009; Yan et al. 2011). The atmospheric circulations over East Asia remotely forced by CT and WP El Niño show great discrepancies throughout the period linked to the diverse SSTAs' structure and evolution. In the developing summer, the western Pacific subtropical high (WPSH) tends to retreat southeastward during CT El Niño but to intensify and advance northwestward during WP El Niño (Weng et al. 2007). During the mature and decaying phases, the abnormal anticyclone over the Philippine Sea (PSAC; Wang et al. 2000) is strong and shows an eastward migration from the northern Indian Ocean (IO) to the east of the Philippine Sea during CT El Niño; however, it is weak, short-lived, and confined to the South China Sea without eastward migration during WP El Niño (Yuan et al. 2012). In the decaying summer, the WPSH shifts westward during CT El Niño, while it reinvigorates after short-term weakness during WP El Niño (Feng et al. 2011). Given the great discrepancies in the responses of atmospheric circulations over East Asia and the importance of these circulations to water vapor transport, it is worth investigating how the two types of El Niño affect water vapor transport and thus the moisture supply to eastern China.

The two types of El Niño have significantly different impacts on the dry/wet condition over East Asia during their lifetime. In the ensuing fall, eastern China tends to be drier than normal because of the northerly flow connected to a weak cyclone anomaly over the western North Pacific (WNP) during WP El Niño, whereas it tends to be wetter than normal resulting from the southwesterly flow associated with the WNP anticyclone during CT El Niño (Zhang et al. 2011). In the mature phase, the opposite dry/wet conditions during the two types of El Niño over southeastern China persist (Weng et al. 2009). In the decaying spring, a slight rainfall deficit is observed over China during WP El Niño, whereas a rainfall surplus is found south to the Yangtze River during CT El Niño (Feng and Li 2011). In the subsequent summer, the rainfall surplus over the Yangtze River associated with CT El Niño continues, while a rainfall deficit exists in the northern Yangtze-Huaihe River region and southeastern China. In contrast, the rainfall is below normal in southern China but above normal over the Huaihe-Yellow River basin during WP El Niño (Feng et al. 2011).

In general, the two types of El Niño have nearly opposite impacts on the rainfall over eastern China throughout their lifetime. WP El Niño tends to induce a greater possibility of drought over eastern China than CT El Niño. Combining these two different phenomena may increase the difficulty in understanding their individual climate impacts (Weng et al. 2007, 2009). Given the great importance of moisture transport in modulating regional rainfall, discrepancies between CT and WP El Niño, and the likelihood of more frequent WP El Niño under global warming (Yeh et al. 2009), it is worth investigating how the two types of ENSO events individually affect the moisture circulation and thus the moisture budget over eastern China. In this paper, the data and methodology are described in section 2. The evolutions of the diverse SSTAs during CT and WP El Niño are examined in section 3; the modulation intensities of the two types of El Niño on the water vapor transport are investigated in section 4 , and the impacts of the them on the water vapor transport and moisture budget over eastern China are compared in section 5. A summary and discussion follow in section 6 .

\section{Data and methodology}

The European Centre for Medium-Range Weather Forecasts (ECMWF) Interim Re-Analysis (ERAInterim) is the one of the latest global atmospheric reanalysis produced by ECMWF to prepare for the next-generation reanalysis to replace the 40-yr ECMWF Re-Analysis (ERA-40; Dee et al. 2011). ERA-Interim improves many of the problems experienced with ERA40 in the hydrological cycle, such as excessive precipitation over the tropical oceans, exaggerated total column water vapor, and the global imbalance of precipitation and evaporation. The precipitation rates from ERA-Interim show closer agreement with the observation-based precipitation data than those from ERA-40 and do not show the excessive rainfall seen in ERA-40 following the eruption of Pinatubo (Dee and Uppala 2008). Comparisons with datasets from other sources were also performed and it is found that ERA-Interim shows greater skill in revealing the global monsoon precipitation than do the National Centers for Environmental Prediction (NCEP)-U.S. Department of Energy (DOE) Global Reanalysis 2 (NCEP-2), ERA-40, and the 25-year Japanese Reanalysis (JRA-25) (Lin et al. 2014). However, caution still need to be used as the precipitation in reanalyses is still commonly overestimated (Feng and Zhou 2012). The gridded $\left(1.5^{\circ} \times\right.$ $\left.1.5^{\circ}\right)$ monthly ERA-Interim data during the period 1979-2012 were employed in this study.

The global Hadley Centre Sea Ice and Sea Surface Temperature dataset (HadISST; Rayner et al. 2003) with a horizontal resolution of $1^{\circ} \times 1^{\circ}$ during the period 1979-2012 is applied in this study. Considering that the Niño-3 and Niño-4 regions capture the main signals of the two different types of El Niño, the $N_{\mathrm{CT}}$ and $N_{\mathrm{WP}}$ indices, which are transformed simply from the Niño-3 $\left(N_{3}\right)$ and Niño-4 $\left(N_{4}\right)$ SST indices (Ren and Jin 2011), 


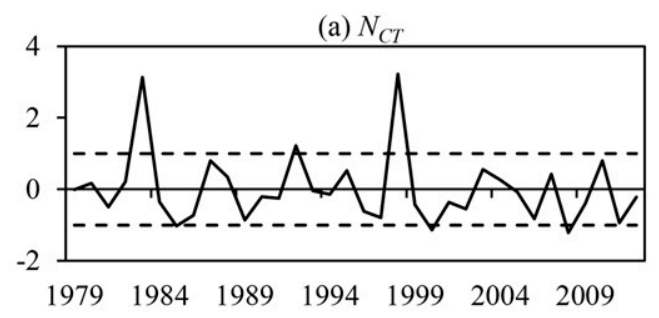

(c) Regressed SST (Nct)

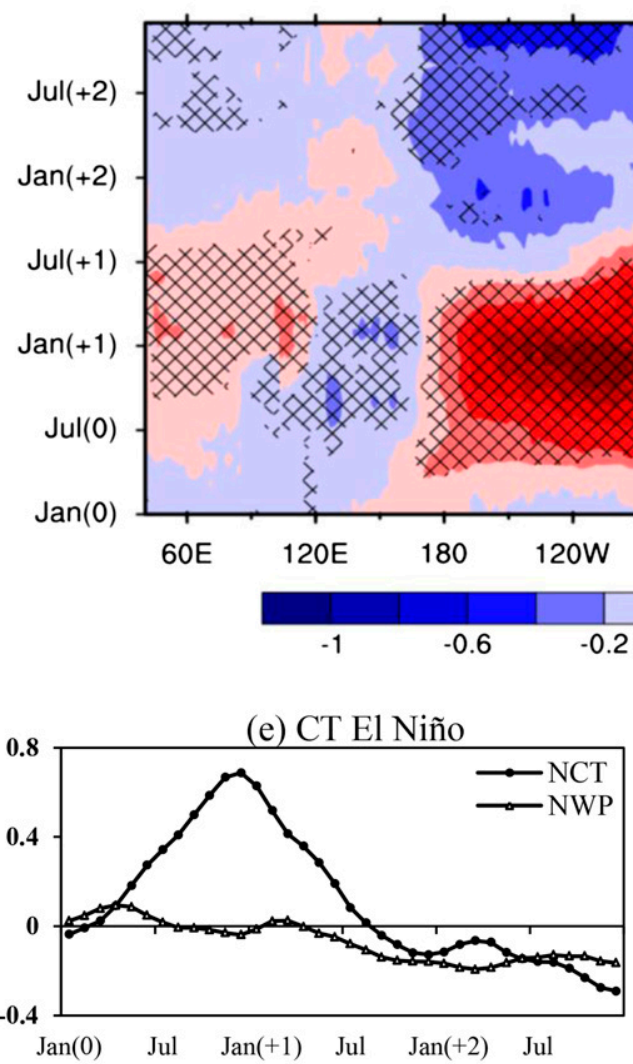

(b) $N_{W P}$

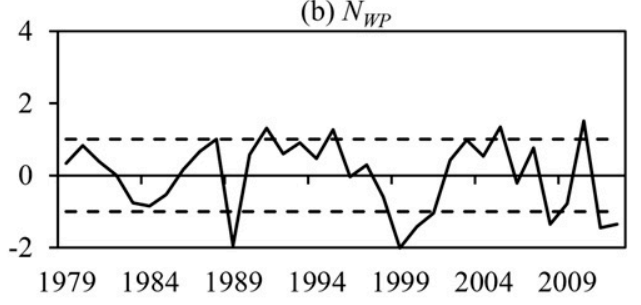

(d) Regressed SST (Nwp)

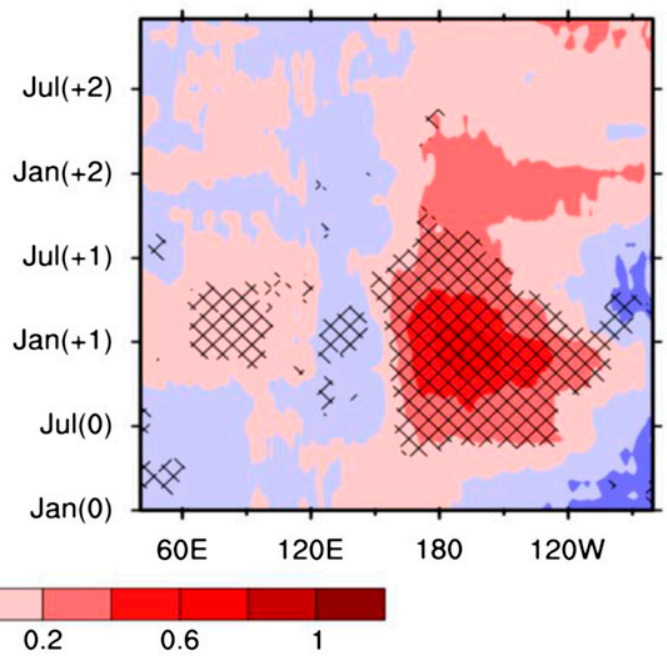

(f) WP El Niño

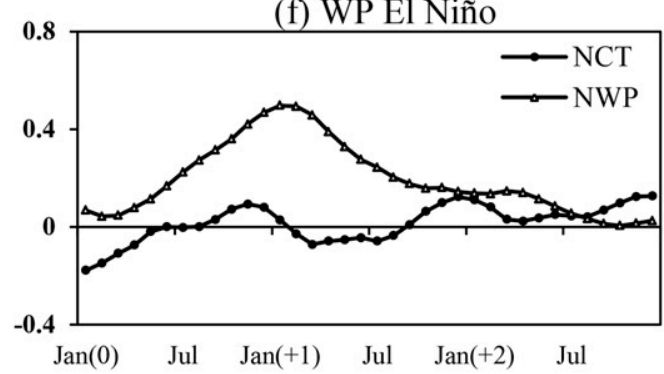

FIG. 1. Time series of the standardized DJF (a) $N_{\mathrm{CT}}$ and (b) $N_{\mathrm{WP}}$ indices during 1979-2012 and the temporal-zonal $5^{\circ} \mathrm{S}-5^{\circ} \mathrm{N}$ averaged SSTAs partially regressed based on the standardized DJF (c) $N_{\mathrm{CT}}$ and (d) $N_{\mathrm{WP}}$ indices from January(0) to December(+2). Also shown are the monthly evolution of the (e) $N_{\mathrm{CT}}$ and (f) $N_{\mathrm{WP}}$ indices derived from the regressed SSTAs. The dashed lines in (a) and (b) indicate the \pm 1 standard deviation. The hatching in (c) and (d) shows where the regression is significant at the $95 \%$ confidence level.

are employed in this study to represent the CT and WP types of El Niño, respectively:

$$
\left\{\begin{array}{ll}
N_{\mathrm{CT}}=N_{3}-\alpha N_{4} \\
N_{\mathrm{WP}}=N_{4}-\alpha N_{3}
\end{array}, \quad \alpha=\left\{\begin{array}{cl}
2 / 5, & N_{3} N_{4}>0 \\
0, & \text { otherwise }
\end{array} .\right.\right.
$$

It should be pointed out that $N_{\mathrm{CT}}$ and $N_{\mathrm{WP}}$ are highly correlated with $N_{3}$ and $N_{4}$ respectively (0.98 and 0.90), while the correlation between $N_{\mathrm{CT}}$ and $N_{\mathrm{WP}}$ is only 0.28 , substantially dropping from a high correlation between $N_{3}$ and $N_{4}(0.81)$. Overall $N_{\mathrm{CT}}$ and $N_{\mathrm{WP}}$ tend to capture well the SST patterns of the two types of El
Niño without overlapping each other. The time series of December-February (DJF) averaged $N_{\mathrm{CT}}$ and $N_{\mathrm{WP}}$ during 1979-2012 are shown in Figs. 1a and 1b.

In this study, to identify the individual signals or impacts of CT and WP El Niño, binary linear regression is employed. This method attempts to model the relationship between two explanatory variables $\left(x_{1}\right.$ and $\left.x_{2}\right)$ and a response variable $y$ by fitting a linear equation to the observed data:

$$
\hat{y}_{i}=\hat{\beta}_{0}+\hat{\beta}_{1} x_{1 i}+\hat{\beta}_{2} x_{2 i} .
$$


The formulas for the least squares estimates in the case of simple regression are

$$
\begin{aligned}
& \hat{\beta}_{0}=\bar{y}-\hat{\beta}_{1} \overline{x_{1}}-\hat{\beta}_{2} \overline{x_{2}}, \\
& \hat{\beta}_{1}=\frac{\sum x_{1 i}^{\prime} y_{i}^{\prime} \sum x_{2 i}^{\prime 2}-\sum x_{2 i}^{\prime} y_{i}^{\prime} \sum x_{1 i}^{\prime} x_{2 i}^{\prime}, \text { and }}{\sum x_{1 i}^{\prime 2} \sum x_{2 i}^{\prime 2}-\left(\sum x_{1 i}^{\prime} x_{2 i}^{\prime}\right)^{2}} \\
& \hat{\beta}_{2}=\frac{\sum x_{2 i}^{\prime} y_{i}^{\prime} \sum x_{1 i}^{\prime 2}-\sum x_{1 i}^{\prime} y_{i}^{\prime} \sum x_{1 i}^{\prime} x_{2 i}^{\prime}}{\sum x_{1 i}^{\prime 2} \sum x_{2 i}^{\prime 2}-\left(\sum x_{1 i}^{\prime} x_{2 i}^{\prime}\right)^{2}}
\end{aligned}
$$

Herein SPR, SUM, AUT, and WIN indicate the boreal spring, summer, autumn, and winter. Also, year(0) is defined as the year in which an El Niño develops and matures, and $-n$ and $+n$ in parentheses refer to $n$ years before and after year(0), respectively.

\section{SSTA evolution in CT and WP El Niño}

The SSTAs partially regressed based on the $N_{\mathrm{CT}}$ and $N_{\text {WP }}$ indices are shown in Figs. 1c and 1d. For CT El Niño, the warming SSTAs first appeared over the coastal eastern Pacific and then extended to the central Pacific with the cooling SSTAs developing simultaneously over the western Pacific. CT El Niño tended to develop in spring, mature in winter, and decay in the ensuing summer followed by a developing cool event. Over the IO, a positive Indian Ocean dipole (IOD; Saji et al. 1999) pattern occurred in the developing phases (Wallace et al. 1998; Wang et al. 2003) and grew into a basinwide warming in the mature phase. This basinwide warming remained until the decaying summer with the warming expanding to the South China Sea (SCS) and even to the east of the Philippines. In contrast, the cooling water over the WNP retreats eastward and significantly persists until June $(+1)$ over the subtropical WNP. Both the Indian Ocean basinwide warming and WNP cooling contribute to the maintenance of the anomalous anticyclone over the western North Pacific, with the latter functioning during the mature winter to the decaying June $(+1)$ via the positive evaporation-wind-SST feedback (Wu et al. 2009, 2010), while the former acts like a capacitor, anchoring the anomalous anticyclone in the decaying summer via the Kelvin wave-induced Ekman divergence mechanism (Xie et al. 2009). In contrast, for WP El Niño, obvious warming first appeared over the tropical central Pacific in its developing summer and showed no significant extension, with cooling SSTAs on its eastern and western flanks. The warming SSTAs reached their maximum in winter, then decayed slightly and extended eastward, persisting until the following year. WP El Niño tended to develop episodically instead of cyclically. It is important to note that
WP El Niño shows a much weaker teleconnection with the SSTAs over the IO (Kao and Yu 2009).

The evolution of the $N_{\mathrm{CT}}$ and $N_{\mathrm{WP}}$ indices (Figs. 1e,f) shows consistent results. During CT El Niño, $N_{\mathrm{CT}}$ showed significant variation while $N_{\mathrm{WP}}$ remained stable, and the opposite occurs for WP El Niño, implying once more that the $N_{\mathrm{CT}}$ and $N_{\mathrm{WP}}$ indices not only adequately represented the two types of El Niño but also separated the SSTA signals from each other.

\section{Seasonal asymmetries in the modulation intensity}

The moisture circulation over eastern China exhibits energetic variations ( $\mathrm{Li}$ et al. 2011, 2012; $\mathrm{Li}$ and Zhou 2012). Connected to different rainfall anomaly patterns, the abnormal water vapor transport shows different behaviors and origins (Zhou and Yu 2005). Before comparing the different impacts of CT and WP El Niño on the moisture circulation over eastern China, the proportion of variances explained (PVE) by the two types of El Niño in the water vapor fluxes from the developing to decaying summer were examined (Fig. 2). This disclosed to what extent CT and WP El Niño modulated the moisture circulation. The most dominant feature in Fig. 2 was the seasonal asymmetry in the modulation intensity of the two types of El Niño. The moisture circulation over China was strongly affected by WP El Niño in the developing summer, but by CT El Niño during the developing fall to the decaying summer. In the developing summer, the influence of WP El Niño was strong over southern China, whereas the influence of CT El Niño was constrained to the south of $20^{\circ} \mathrm{N}$. In the ensuing fall, the influence of CT El Niño was obviously enhanced, with the zonal transport over southern China strongly affected; however, the influence of WP El Niño retreated from eastern China and shifted southeastward to the WNP. In the mature winter, a vast region extending from southern China to the south of Japan was dominated by CT El Niño. In the following spring, the affected region extended northward to the eastern part of northern China; influence from WP El Niño also appeared over southern China, but to a much lesser extent. In the decaying summer, water vapor transport over a large portion of China was strongly influenced by CT El Niño, with the explained variance over $30 \%$ in some key regions, while WP El Niño made almost no contribution.

In summary, the influences of CT and WP El Niño on water vapor transport over China differed greatly during each phase. The short impact of WP El Niño mainly took place in the developing summer and fall, and decayed in the following seasons, whereas the long impact of CT El Niño lasted from the developing fall to the decaying summer. 
(a) $\operatorname{Cov}(\mathrm{CT}) \operatorname{SUM}(0)$

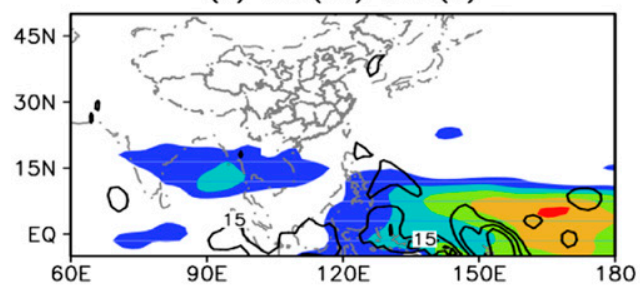

(c) $\operatorname{Cov}(\mathrm{CT}) \operatorname{AUT}(0)$

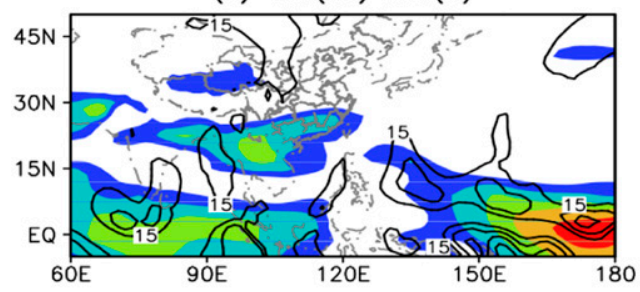

(e) $\operatorname{Cov}(\mathrm{CT}) \operatorname{WIN}(0)$

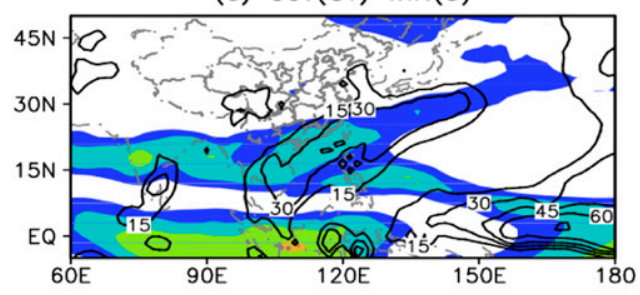

(g) $\operatorname{Cov}(\mathrm{CT}) \operatorname{SPR}(+1)$

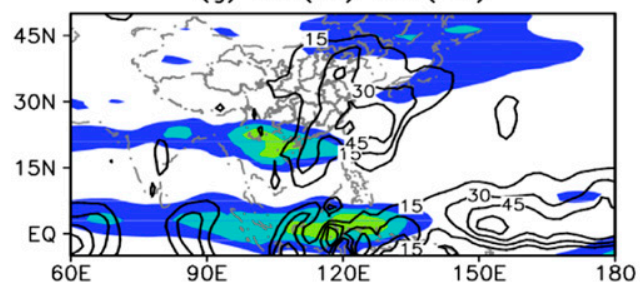

(i) $\operatorname{Cov}(\mathrm{CT}) \operatorname{SUM}(+1)$

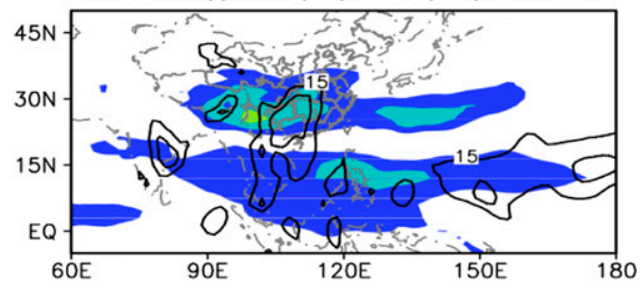

(b) $\operatorname{Cov}(W P) \operatorname{SUM}(0)$

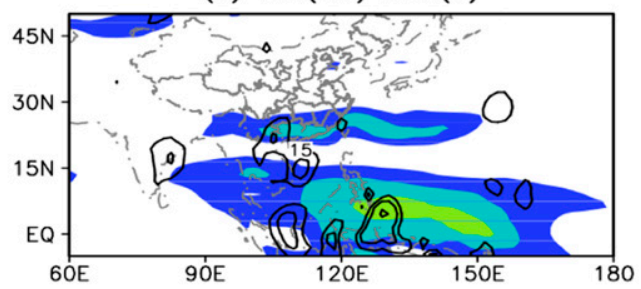

(d) $\operatorname{Cov}(W P) \operatorname{AUT}(0)$

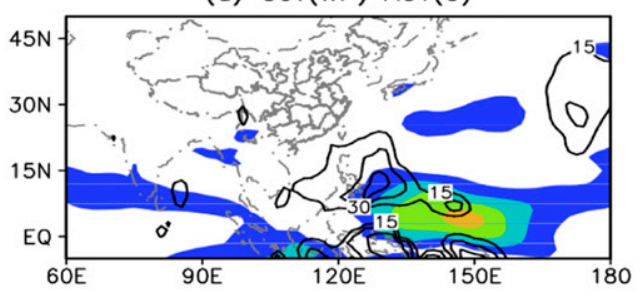

(f) $\operatorname{Cov}(W P) \operatorname{WIN}(0)$

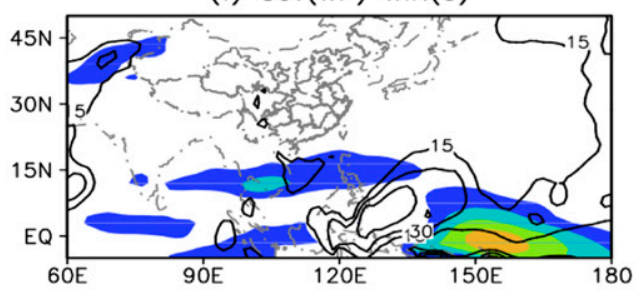

(h) $\operatorname{Cov}(\mathrm{WP}) \operatorname{SPR}(+1)$

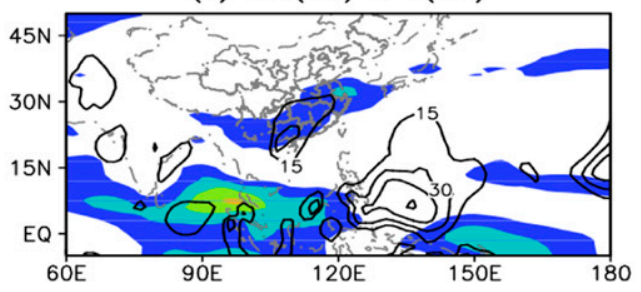

(j) $\operatorname{Cov}(W P) \operatorname{SUM}(+1)$

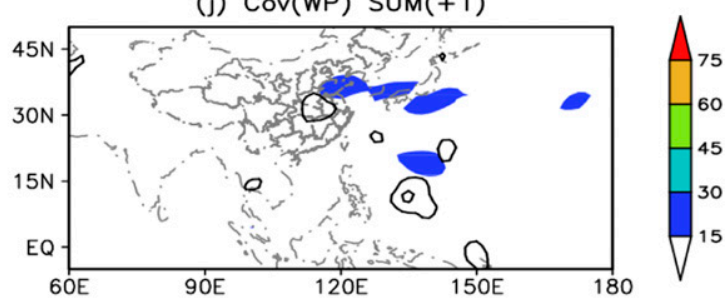

FIG. 2. Explained variances (\%) of the zonal (shading) and meridional (contour) water vapor fluxes partially regressed by DJF (left) $N_{\mathrm{CT}}$ and (right) $N_{\mathrm{WP}}$ indices from (top) $\operatorname{SUM}(0)$ to (bottom) $\operatorname{SUM}(+1)$.

\section{Diverse responses of moisture transport and moisture budget}

\section{a. Water vapor transport and divergence}

To demonstrate how the two types of El Niño affect the moisture circulation over eastern China respectively, the vertical integral of the water vapor flux and its divergence were partially regressed based on the $N_{\mathrm{CT}}$ and $N_{\text {WP }}$ indices (Fig. 3).

In the developing summer of CT El Niño, the southerly transport over eastern China was weakened as abundant moisture from the IO was transported eastward to the WNP instead of northward to eastern China, because of an anticyclonic moisture circulation over the IO and a strong westerly transport over the tropical western Pacific. It caused a moisture deficit over northern China and a moisture surplus over southern China. In the developing fall, the anticyclonic moisture circulation expanded from the IO to the SCS; a vast region over the SCS and Maritime Continent was subjected to moisture divergence, with abnormal easterly moisture transport to its west and abnormal westerly moisture 
(a) CT ENSO SUM(O)

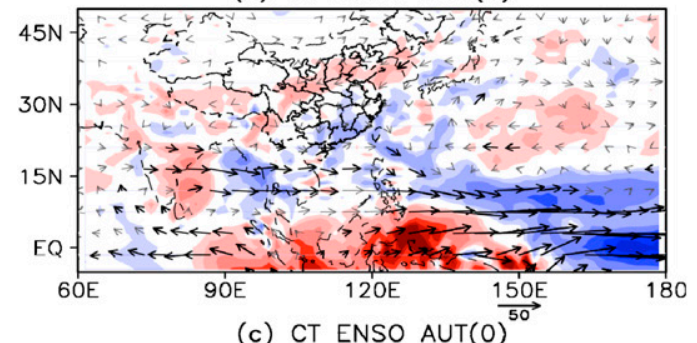

(c) CT ENSO AUT(O)

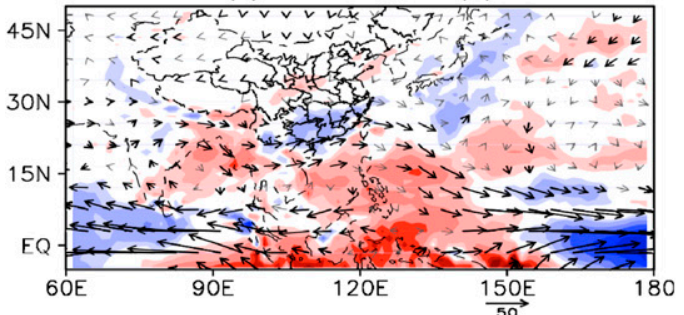

(e) CT ENSO WIN $(0)^{50}$

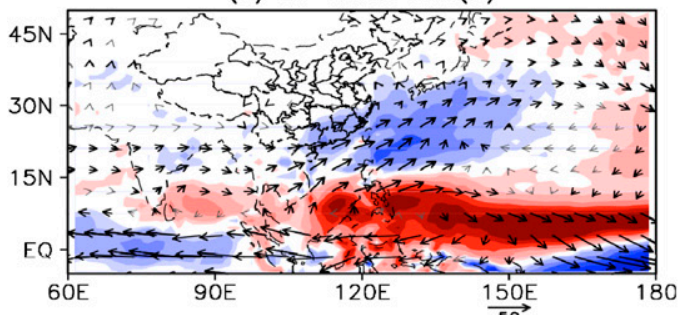

(g) CT ENSO $\operatorname{SPR}(+1)^{50}$

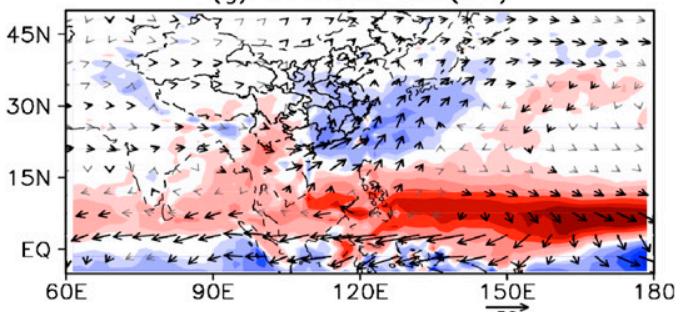

(i) CT ENSO $\operatorname{SUM}(+1)$
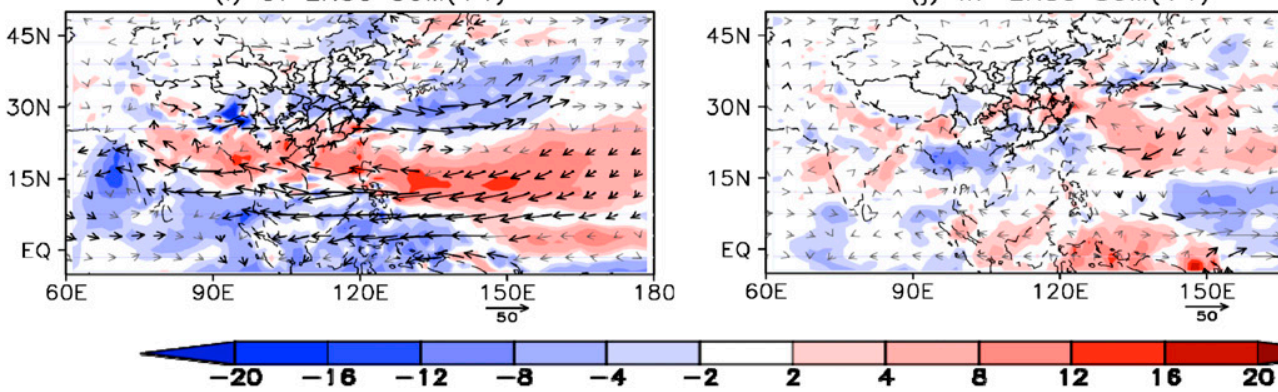

FIG. 3. Partial regression of seasonal vertical integral of water vapor flux $\left(\mathrm{kg} \mathrm{m}^{-1} \mathrm{~s}^{-1}\right.$; vector $)$ and its divergence $\left(10^{-6} \mathrm{~kg} \mathrm{~m}^{-2} \mathrm{~s}^{-1}\right.$; shading) based on the DJF (left) $N_{\mathrm{CT}}$ and (right) $N_{\mathrm{WP}}$ indices from (top) SUM(0) to (bottom) SUM(+1). (b) WP ENSO SUM(O)
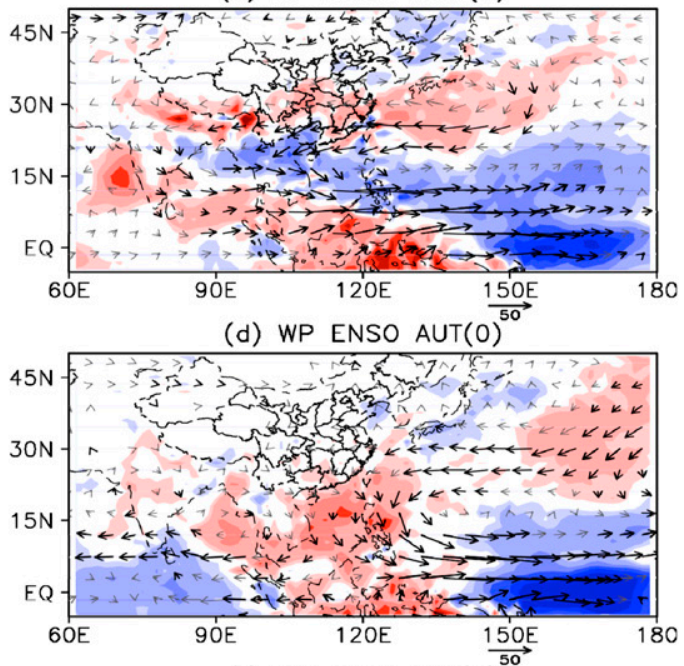

(f) WP ENSO WIN(O)

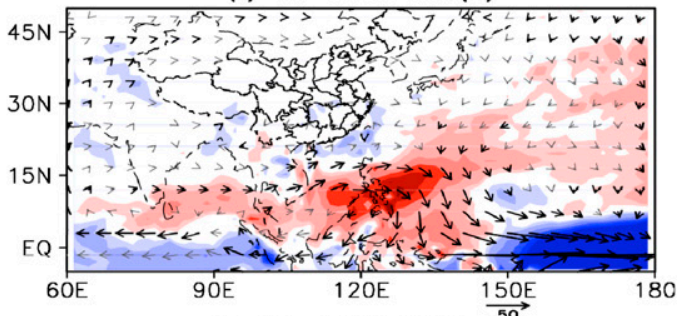

(h) WP ENSO $\operatorname{SPR}(+1)^{50}$

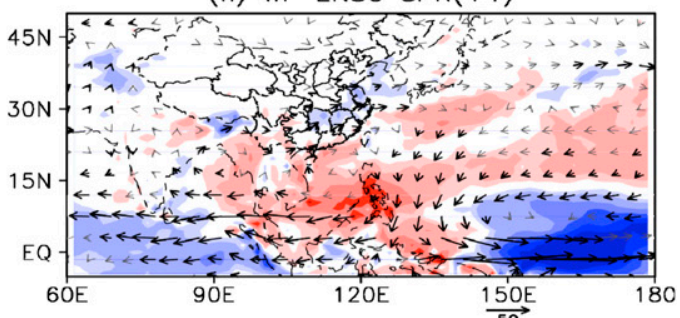

(j) WP ENSO $\operatorname{SUM}(+1)$

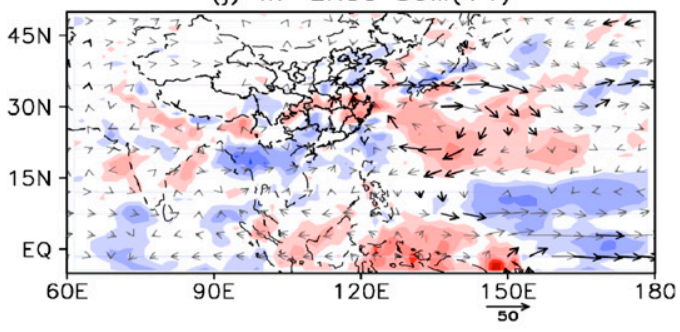

transport to its east. To the north of the anticyclone, abnormal southwesterly transport dominated southeastern China and caused above-normal moisture convergence. In the mature winter, the anticyclone was stably established over the SCS-Philippine Sea area (PSAC; Wang et al.2000), with intense moisture divergence underneath.
The peripheral southwesterly moisture transport converged with the enhanced westerly moisture transport over the northern SCS and then invaded southeastern China and the WNP, resulting in strong moisture convergence over southeastern China. In the ensuing spring, the abnormal moisture circulation persisted and extended even 
farther to northern China, causing enhanced moisture convergence throughout eastern China. In the decaying summer, the widespread anticyclonic moisture circulation shifted northward and dominated the subtropical WNP, ushering in a moisture deficit over southeastern China and a moisture surplus to the north over the Yangtze River valley and northern China.

In contrast, WP El Niño imposed robust influences on the moisture circulation over eastern China in the developing summer. An abnormal anticyclonic circulation appeared to the north over the Yangtze River valley and a cyclonic circulation lay to the south over the northern SCS. Less-than-normal moisture was transported from the low latitudes to eastern China, while the export of moisture from the Yangtze River valley was enhanced, ushering in a moisture deficit in the Yangtze River valley and the northern part of southern China but a moisture surplus over northern and northeastern China. The anticyclonic moisture circulation to the north decayed in the following fall and the cyclonic one to the south shifted eastward, withdrawing its steering northerly flow from eastern China in the mature winter. A weak anticyclonic moisture circulation was established over the central SCS, with the diverged moisture transported to the northern coast of the SCS. In this stage, the influence of WP El Niño on the moisture sink over eastern China was negligible. In the ensuing spring, the abnormal anticyclone over the SCS showed no obvious eastward migration but a slight extension to the north. In contrast to the vast anticyclonic moisture circulation during CT El Niño, this was much weaker, smaller, and short-lived. The moisture diverged over the SCS was transported to the northern part of southern China and the Yangtze River valley. Overall, the impact of WP El Niño on the water vapor transport over eastern China mainly appeared in the developing summer and fall, inducing a moisture deficit in the Yangtze River valley and southeastern China sequentially.

These diverse moisture circulations are a result of the distinctive atmospheric responses to the two types of ENSO. The PSAC, strengthened by the remote CT El Niño forcing, tropical-extratropical interaction, and monsoon-ocean interaction (Wang and Zhang 2002), helped transport stronger-than-normal moisture into eastern China during the developing fall to the decaying spring of CT El Niño. In contrast, the cyclone anomaly over the WNP motivated by the abnormal ascending motion over the central Pacific (not shown) favored weaker-than-normal moisture transport to eastern China in the developing summer and fall of WP El Niño. The southwestward shift of the WPSH dominated the moisture circulation over China in the decaying summer of CT El Niño, but not WP El Niño (Feng et al. 2011).
For both CT and WP El Niño, the abnormal meridional transport divergence was nearly the opposite of the zonal transport divergence, with a slightly larger magnitude (Fig. 4). The total moisture divergence was the small difference between them and showed a similar pattern to the meridional moisture divergence. Thus, although the magnitude of the zonal water vapor transport was strong, most of the moisture was transported out of eastern China directly, and although the meridional water vapor flux was weak, its convergence efficiency was high; the moisture divergence issued by the meridional flux was even larger that by the zonal flux over eastern China. That is, the abnormal moisture divergence over eastern China was dominated by the meridional, rather than the zonal, moisture transport anomalies.

\section{b. Moisture budget}

The investigation of the vertical integral of water vapor flux provided insight into how the two types of El Niño affect moisture circulation over eastern China. This helps ascertain which circulation is crucial to the moisture supply and where the abnormal moisture probably originates. However, the results are qualitative, and a more quantitative assessment is desirable. To achieve this, the net regional moisture budget (Fig. 5) was calculated in three regions within eastern China from south to north, that is, southeastern China (SE), the Yangtze River valley (YZ), and the eastern part of northern China (ENC). CT and WP El Niño induced completely different impacts on the moisture budget over eastern China. For CT El Niño, SE experienced an enhanced moisture surplus during the developing summer to the decaying spring but a serious moisture deficit in the decaying summer; the $\mathrm{YZ}$ did not receive a robust moisture surplus until the decaying spring and summer. ENC suffered from a severe moisture deficit in the developing summer but a moisture surplus in the decaying spring. For WP El Niño, the moisture budget over eastern China was much less affected. The most dramatic features were the strong moisture deficits over the $\mathrm{YZ}$ in the developing summer and over SE in the developing fall. It is important to note that the winter WP El Niño does not predict a severe flooding but only causes a weak moisture deficit over the $\mathrm{YZ}$ in the decaying summer. Thus, the moisture supplies over eastern China are completely different during each phase of the two types of El Niño.

To check whether a baroclinic structure existed, the vertical profiles of the regressed net regional moisture budget and moisture transport via each boundary were also examined (Figs. 6 and 7). For CT El Niño, great seasonal asymmetry appeared; the abnormal moisture transport via each boundary was weak in $\operatorname{SUM}(0)$ but 

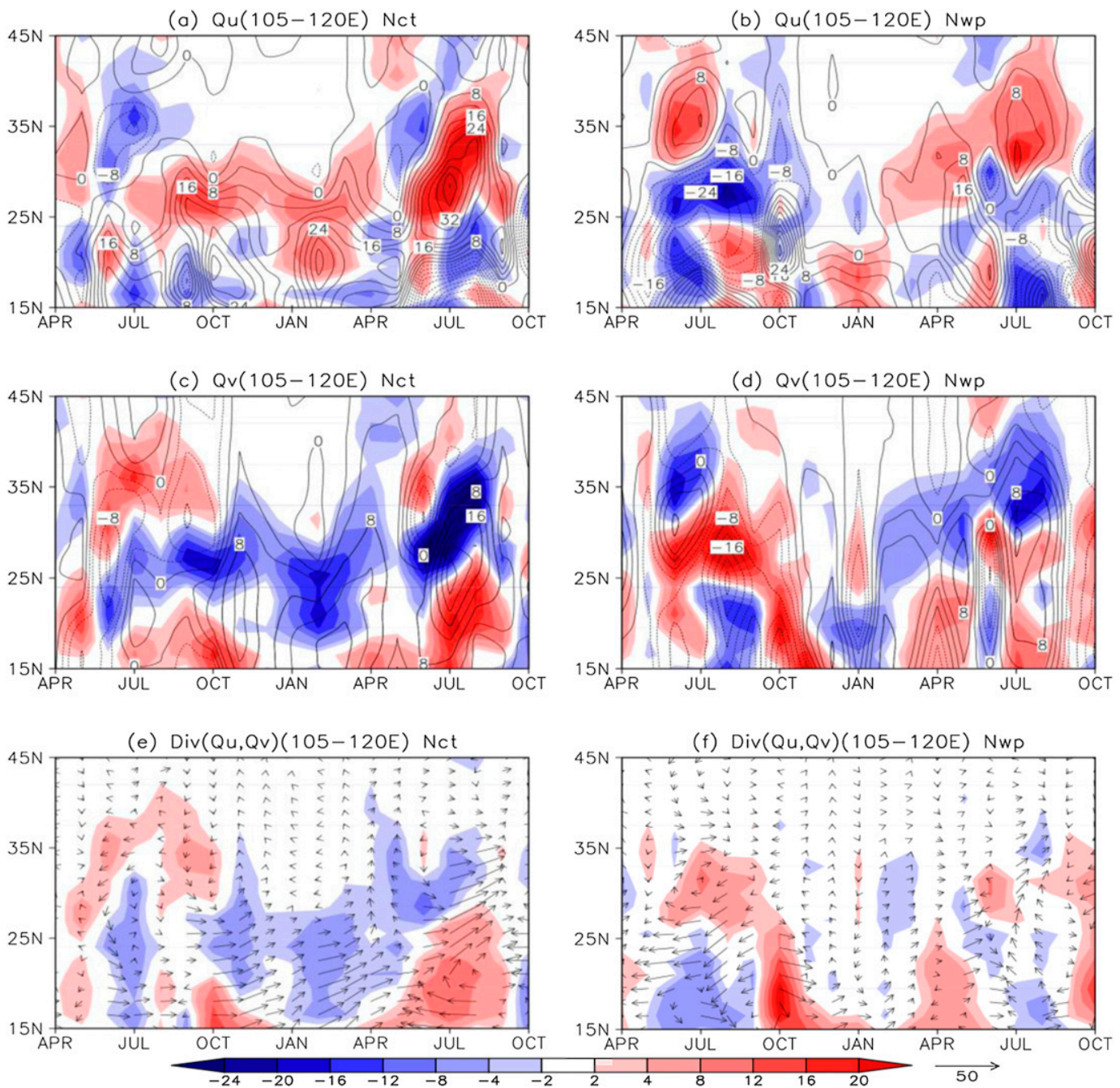

FIG. 4. Temporal-meridional sections of the $105^{\circ}-120^{\circ} \mathrm{E}$ averaged vertical integral of (a),(b) zonal water vapor flux (contour) and its divergence (shading), (c),(d) meridional water vapor flux and its divergence, and (e),(f) both zonal and meridional water vapor fluxes (vector) and their divergence (shading) partially regressed by DJF (left) $N_{\mathrm{CT}}$ and (right) $N_{\mathrm{WP}}$ indices from April( $(0)$ to October(+1). (The unit for the water vapor flux is kg m${ }^{-1} \mathrm{~s}^{-1}$, and the unit for the divergence is $10^{-6} \mathrm{~kg} \mathrm{~m}^{-2} \mathrm{~s}^{-1}$.)

strong in SUM(+1) over SE and the YZ (Fig. 6). Over $\mathrm{SE}$, the abnormal moisture transport enhanced from SUM(0) to WIN $(0)$. The southern boundary acted as the most important input boundary, with its maximum near the surface. The western boundary acted as an additional input boundary, with its maximum at around $750 \mathrm{hPa}$. The eastern boundary acted as a key output boundary, with its vertical variation much smoother than the input via the southern/western boundary, might be due to the combined sources from the two boundaries concentrating at different levels. The moisture output via the northern boundary had been strong since $\mathrm{SPR}(+1)$ with its maximum located at around $825 \mathrm{hPa}$, higher than the input via the southern boundary.
Resulting from the combination of different vertical structures of the moisture transport via each boundary, the maximum net regional moisture budget appeared near the surface during $\operatorname{AUT}(0)$ to $\operatorname{SPR}(+1)$ as it was dominated by the southern boundary input; it rises to above $900 \mathrm{hPa}$ in $\operatorname{SUM}(+1)$ as it was dominated by the northern boundary output. Over the YZ, strong abnormal moisture transport took place only in the decaying phases with the input via the southern boundary dominating the net regional moisture budget. Over ENC, the strong moisture deficit in $\operatorname{SUM}(0)$ resulted from the enhanced moisture output via the northern boundary in the lower level coinciding with the weakened moisture input via the southern boundary in the middle level. 

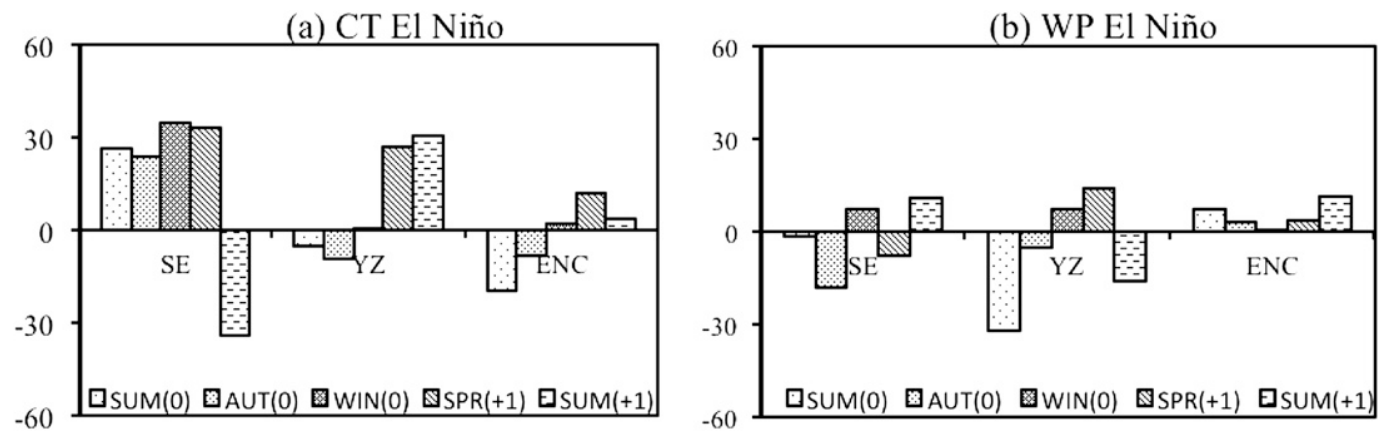

FIG. 5. Partial regression of seasonal regional moisture budget $\left(\mathrm{mm} \mathrm{season}^{-1}\right)$ over southeastern China $\left(21^{\circ}-\right.$ $\left.28.5^{\circ} \mathrm{N}, 105-121.5^{\circ} \mathrm{E}\right)$, the Yangtze River valley $\left(28.5^{\circ}-33^{\circ} \mathrm{N}, 105^{\circ}-121.5^{\circ} \mathrm{E}\right)$, and the eastern part of northern China $\left(33^{\circ}-42^{\circ} \mathrm{N}, 105^{\circ}-121.5^{\circ} \mathrm{E}\right)$ from $\operatorname{SUM}(0)$ to $\operatorname{SUM}(+1)$ based on the DJF (a) $N_{\mathrm{CT}}$ and (b) $N_{\mathrm{WP}}$ indices.

For WP El Niño, the strong regional moisture budget deficit in the YZ in $\operatorname{SUM}(0)$ appeared mainly near the surface (Fig. 7) due to the combined effects of abnormal outputs via both the southern and northern boundaries, whereas the strong regional moisture budget deficit in SE in AUT(0) lay within the lower-middle troposphere, resulting from the strong abnormal moisture output via the southern boundary. It is important to note that the
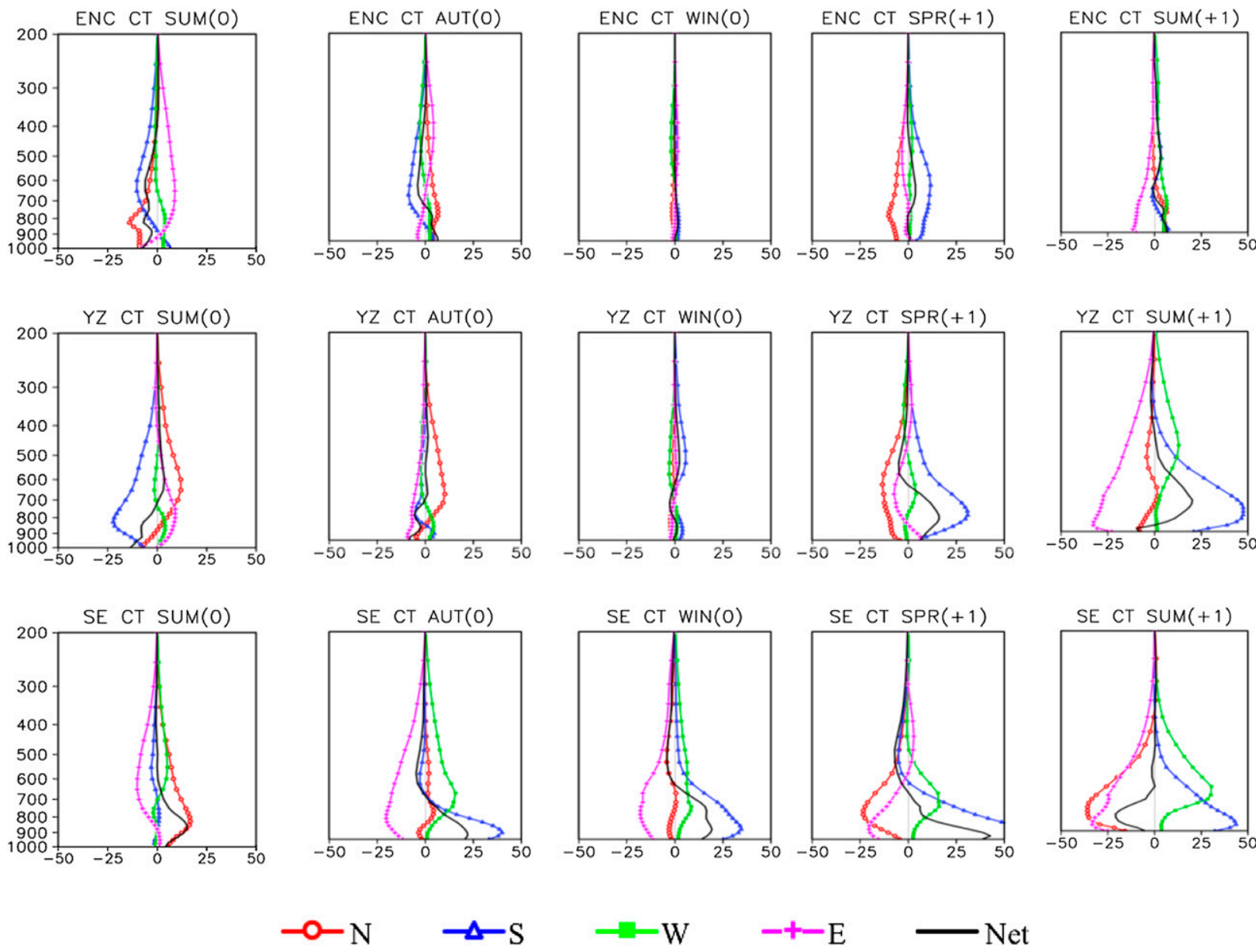

Net

FIG. 6. Vertical profile of moisture transport via each boundary [north (red), south (blue), west (green), and east (magenta)] and net regional moisture budget (black) over (top) ENC, (middle) YZ, and (bottom) SE partially regressed based on the DJF $N_{\mathrm{CT}}$ index from (left) $\operatorname{SUM}(0)$ to (right) $\operatorname{SUM}(+1)\left(10^{-5} \mathrm{~kg}^{-1} \mathrm{~m}^{-1} \mathrm{day}^{-1}\right)$. 

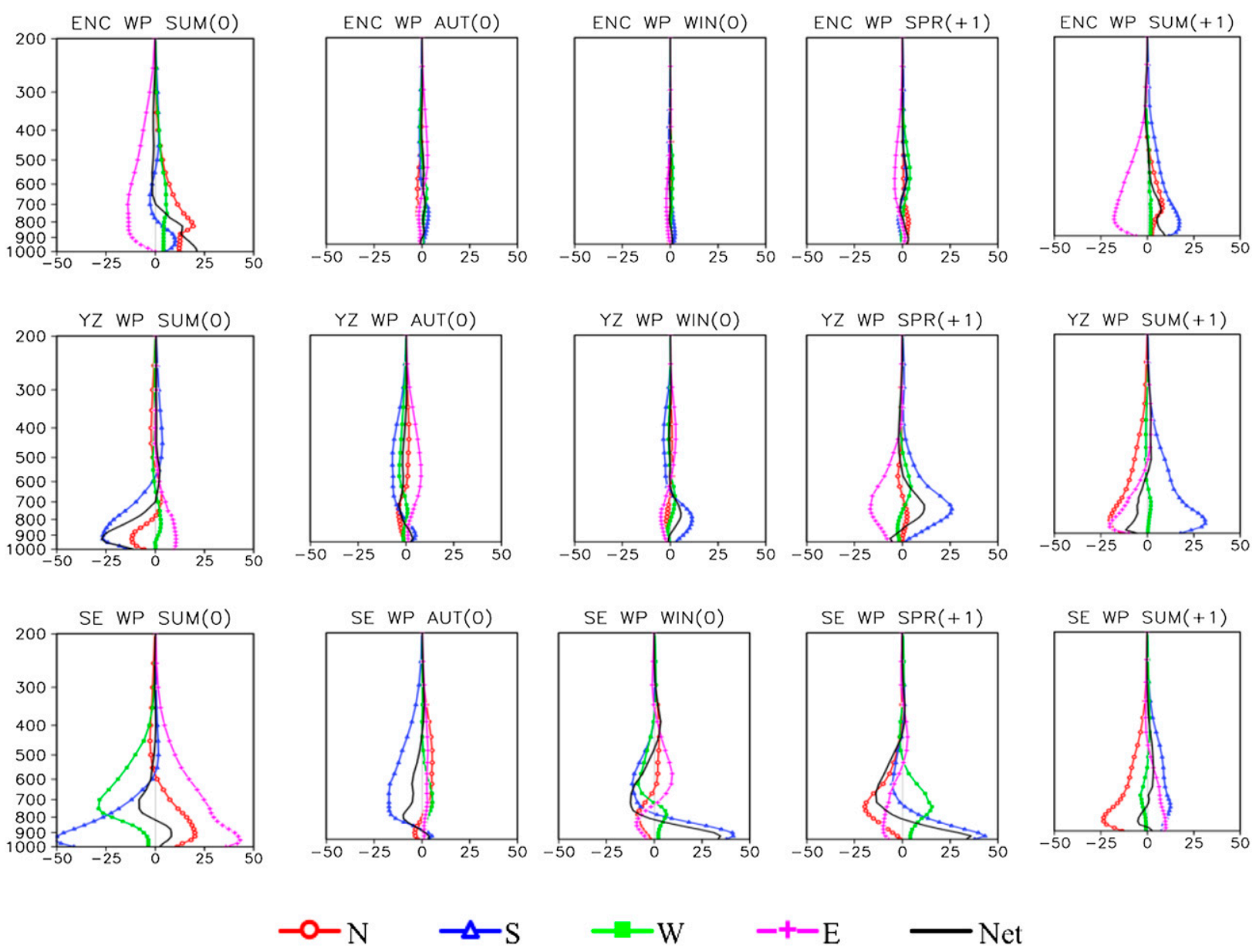

FIG. 7. As in Fig. 6, but for the DJF $N_{\mathrm{WP}}$ index.

regional moisture budget over SE is weakly modulated by WP El Niño during WIN(0) and SPR $(+1)$ from the perspective of the vertical integral in the aforementioned results; however, this is not the whole story. Instead, the influence is strong but shows a baroclinicity with an enhanced moisture surplus near the surface and a moisture deficit within the lower-middle troposphere. To investigate further, the abnormal horizontal moisture transports near the surface $(950 \mathrm{hPa})$ and the lowermiddle level $(700 \mathrm{hPa})$ were compared (Fig. 8$)$. Near the surface, the moisture transport in WIN $(0)$ of both CT and WP El Niño, were dominated by the PSAC, with the former more intensive than the latter. The peripheral southwesterly transport issued in enhanced moisture input via the southern boundary of SE. At $700 \mathrm{hPa}$, the anticyclonic moisture transported by the PSAC was weakened. For CT El Niño, strong westerly transport from the Indian Ocean turned northeastward over the northern SCS and issued in strong moisture input via the southern boundary of SE as advected by the peripheral circulation of the widespread abnormal anticyclone over the Indian Ocean and the WNP. For WP El Niño, the westerly transport from the Indian Ocean was located much farther southward and turned southeastward instead of northeastward over the Philippine Sea as the abnormal anticyclone was much weaker and constrained over the equatorial Indian Ocean and SCS, but not the WNP. Additionally, abnormal northerly transport appeared over southern China advected by the peripheral circulation of an anticyclone over the Tibetan Plateau. This anticyclone dominated the whole troposphere over the Tibetan Plateau (not shown). Thus, the moisture transport via the southern boundary at the lower-middle level was defective. It was the offset between the strong input near the surface and the output at lower-middle level that resulted in the weak response of the vertical integral moisture circulation over SE to WP El Niño in WIN(0). In SPR(+1), the strong input via the southern boundary near the surface transported by the PSAC was offset by the strong output via the northern boundary at 

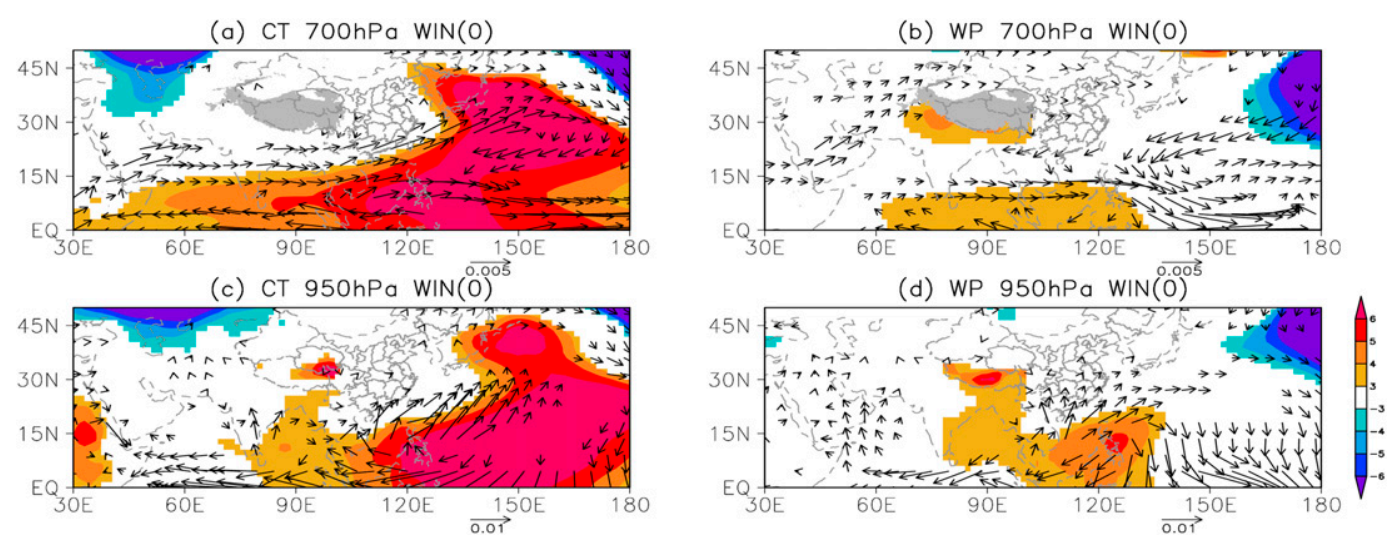

FIG. 8. Partial regression of winter vertical integral of water vapor flux $\left(\mathrm{kg} \mathrm{m}^{-1} \mathrm{~s}^{-1}\right.$; vector) and geopotential height (gpm; shading) at (a),(b) 700 and (c),(d) $950 \mathrm{hPa}$ based on the DJF (left) $N_{\mathrm{CT}}$ and (right) $N_{\mathrm{WP}}$ indices.

the lower-middle level transported by the northeasterly flow of an abnormal anticyclone over the Indochinese Peninsula and SCS (not shown).

Hence, the remote forcing of the two types of El Niño on the moisture circulation is far from barotropic; the strongest variation in the abnormal moisture budget may appear in different levels rather than lying solidly near the surface, where the moisture is abundant. These results give us an incentive to study further the vertical structure of the moisture transport circulation, which is not a matter of concern in previous studies.

\section{c. High consistency in the case studies}

The diverse water vapor transport and moisture budget response for CT and WP El Niño were compared mainly based on the partial regression method in previous sections. To further verify the results, composite studies were launched. Based on the variation of the DJF $N_{\mathrm{CT}}$ and $N_{\mathrm{WP}}$, three CT El Niño (1982/83, 1991/92, and 1997/98) and five WP El Niño (1987/88, 1990/91, 1994/95, 2004/05, and 2009/10) years were selected when the indices were larger than 1 standard deviation. The vertical integral of water vapor fluxes and regional moisture budget anomalies were composited and they show results consistent with those displayed in Figs. 3-5. The vertical profile of the composited moisture transport via each boundary was shown in Figs. 9 and 10. For CT El Niño, not only the seasonal asymmetry but also the diverse vertical structure of moisture transport via each boundary can be well captured in the composite study. For WP El Niño, the strong baroclinicity of the moisture budget over SE in $\operatorname{WIN}(0)$ and $\operatorname{SPR}(+1)$ was also detected in the composite study, although in a weaker manner. Such great consistencies between results from the composite and regression studies verify that the conclusions drawn in this study are reasonable.

\section{Summary and discussion}

With the motivation to reveal how CT and WP El Niño affect the moisture supply over eastern China separately, we compared the water vapor transport and moisture budget over eastern China during the developing summer and the decaying summer. We employed $N_{\mathrm{CT}}$ and $N_{\mathrm{WP}}$, which captured well the SST patterns of the two types of El Niño without overlapping each other, to represent CT and WP El Niño, respectively.

The impacts of the two types of El Niño on the moisture circulation over eastern China show great seasonal asymmetry. The influence of CT El Niño was strong only after the developing fall related to the abnormal anticyclonic moisture transported by the PSAC during the developing fall to the decaying spring and the WPSH in the decaying summer. In contrast, the impact of WP El Niño mainly appeared in the developing summer and fall connected to an anticyclonic moisture circulation over the YZ in the developing summer and a cyclonic one over the SCS in the developing summer and over the tropical western Pacific in the developing fall. It was the meridional rather than the zonal transport divergence that dominated the abnormal moisture divergence over eastern China.

Investigation of the moisture budget shows a more quantitative result. For CT El Niño, SE experienced an enhanced moisture surplus during the developing summer to the decaying spring but a moisture deficit in the decaying summer; the YZ did not receive a robust moisture surplus until the decaying spring and summer. ENC suffered from a severe moisture deficit in the developing summer but a moisture surplus in the decaying spring. For WP El Niño, the most dramatic features were the strong moisture deficits over the YZ in the developing summer and over SE in the developing fall. 

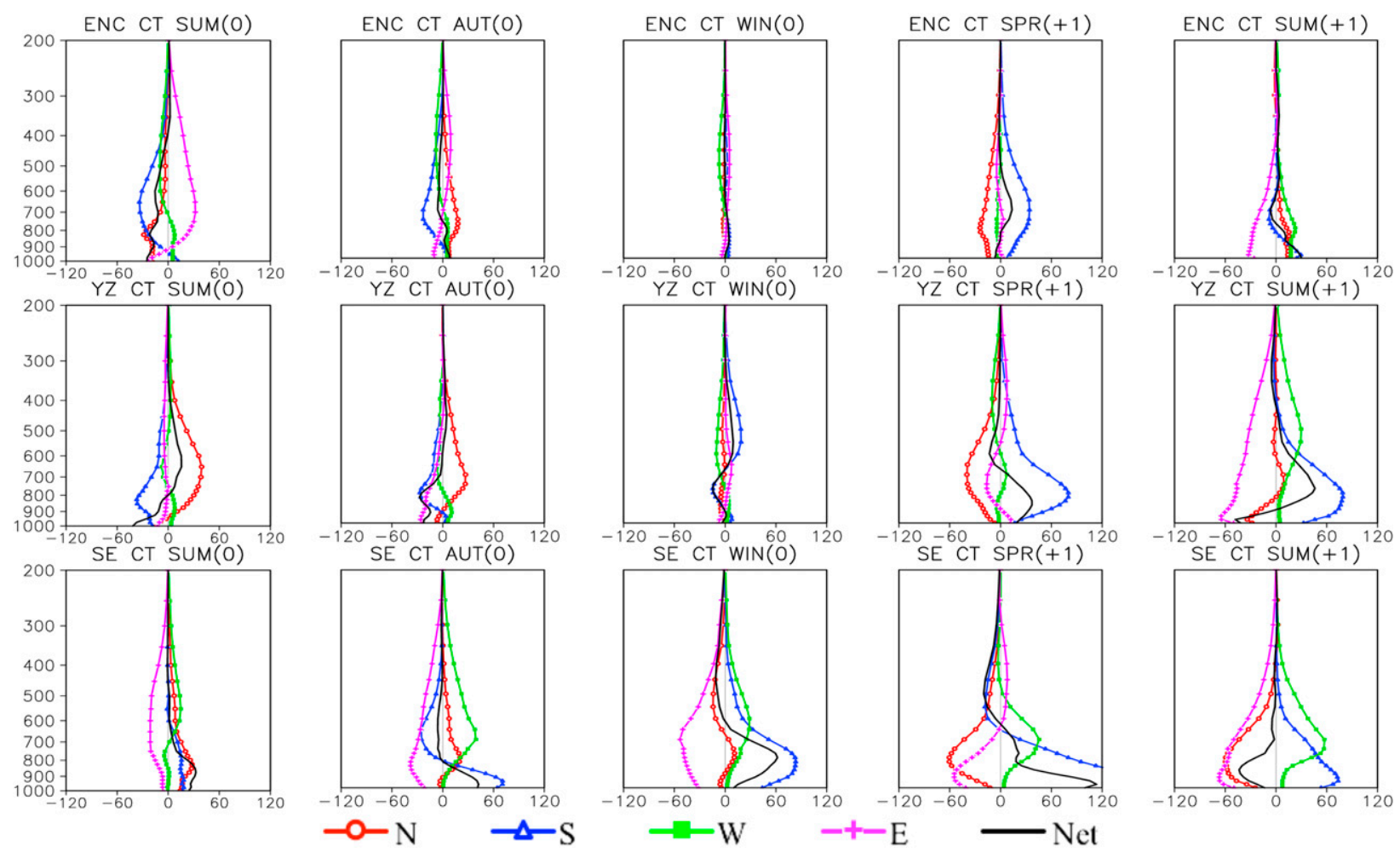

FIG. 9. Vertical profile of moisture transport via each boundary [north (red), south (blue), west (green), and east (magenta)] and net regional moisture budget (black) over (top) ENC, (middle) YZ, and (bottom) SE from (left) SUM(0) to (right) SUM(+1) composited based on the CT El Niño years $\left(10^{-5} \mathrm{~kg}^{-1} \mathrm{~m}^{-1}\right.$ day $\left.{ }^{-1}\right)$.

The vertical structure of the modulated moisture budget showed a great baroclinicity, with the maximum abnormal moisture transport via each boundary appearing in different levels. The enhanced moisture surplus imposed by WP El Niño over SE was offset by a moisture deficit within the lower-middle troposphere due to a diverse response circulation in different vertical levels.

Accurate representation of the hydrological cycle in reanalysis data presents a special challenge as many parameters are constrained only indirectly by observation, such as evaporation and precipitation. The ERAInterim reanalysis dataset was the mere dataset applied in this study, the quality of which can directly disturb the conclusions. To evaluate the ability of ERA-Interim in representing the atmospheric hydrological cycle over eastern China, the mean annual cycle of the individual terms in the water vapor balance equation was calculated (Fig. 11). The most striking feature was that regional moisture convergence and local evaporation are two main moisture sources for precipitation. The moisture divergence showed consistent variation with precipitation but in opposite sign, while the variation of regional evaporation lagged behind that of precipitation, indicating the variation of evaporation tended to be the result instead of the source of the variation of precipitation. Correlation analysis (Fig. 12) disclosed that the variation of seasonal precipitation over eastern China can be well represented by the ERA-Interim (correlation coefficient $>0.5$ ); the variation of seasonal precipitation was largely attributed to the variation of moisture convergence (correlation coefficient $>0.4$ ) instead of local evaporation (correlation coefficient $<0.3$ ). That is also why the moisture circulation instead of evaporation was emphasized to study the diverse impacts of the two types of El Niño on the water supply over eastern China. The local change in precipitable water was much less than other terms, which might not play a significant role in the moisture supply above the monthly scale.

Although the water balance should be closed in theory, the bias $(\langle P\rangle-\langle E\rangle+\langle\nabla \cdot \mathbf{Q}\rangle+\langle\partial W / \partial t\rangle)$ can usually be found in region-averaged atmospheric branch of the hydrological cycle derived from reanalysis data. It also existed in the ERA-Interim; however, it was very small compared to the precipitation, evaporation, and moisture divergence terms. Realizing this small bias in how ERA-Interim represents the water balance, it is still reasonable to apply this reanalysis dataset to study the atmospheric branch of the hydrological cycle over eastern China. 

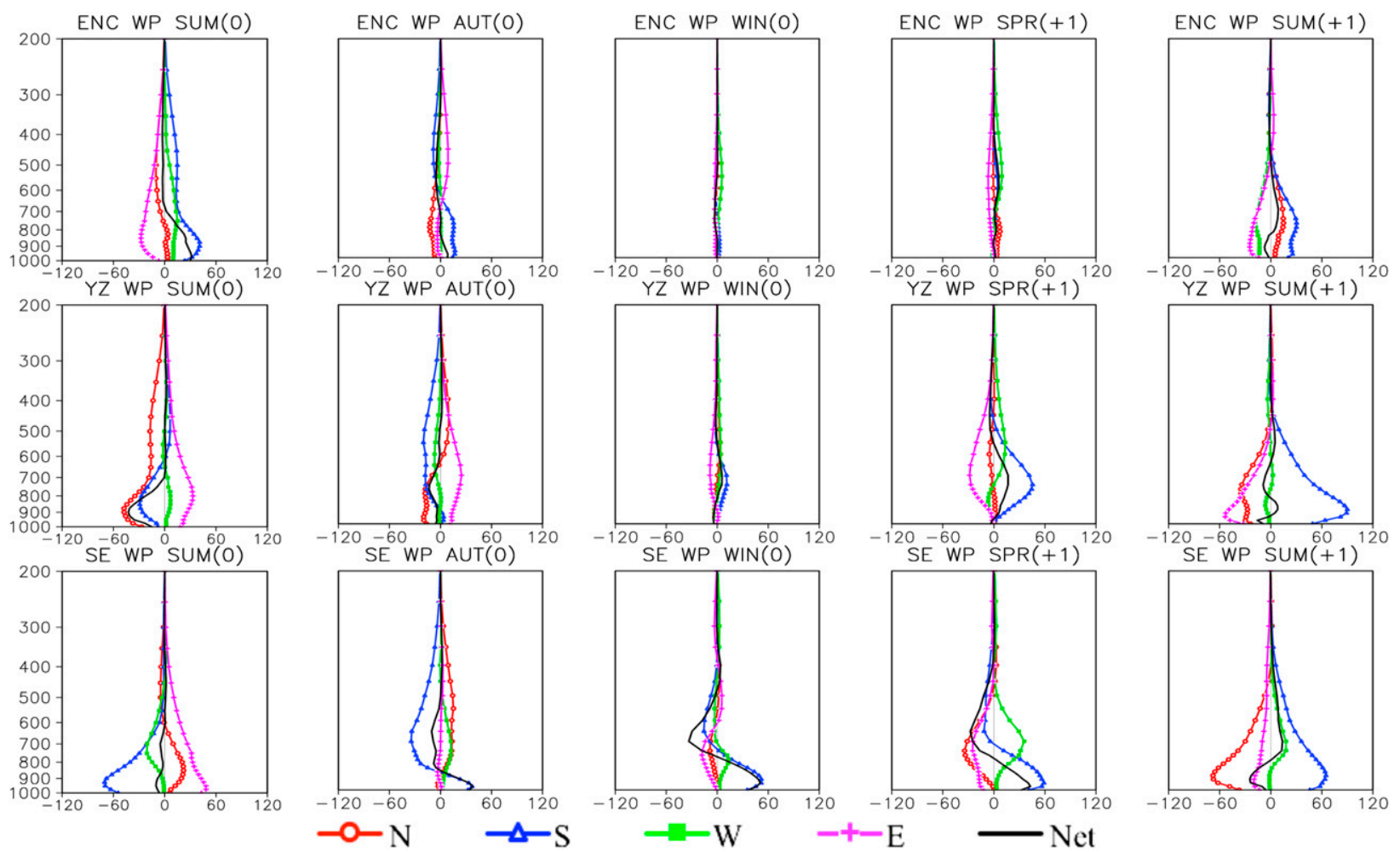

FIG. 10. As in Fig. 9, but for WP El Niño years.

The discrepancies in the abnormal moisture circulations induced by the two types of El Niño are attributed mainly to distinct atmospheric responses, especially the anticyclone over the WNP. The intensity, duration, and migration of this anticyclone show great differences in the two types of El Niño (Yuan et al. 2012), especially in the decaying summer, when the anticyclone is represented as the southwestward shift of the WPSH during
CT El Niño, and disappears during WP El Niño. The mechanism for the maintenance of this WNP abnormal anticyclone in $\operatorname{SUM}(+1)$ has been widely discussed. One commonly accepted hypothesis is the capacitor effect of warming in the Indian Ocean: Indian Ocean warming, charged by the El Niño teleconnection, persists through the summer and anchors the southwestward shift of the WPSH via the Kelvin wave-induced Ekman divergence
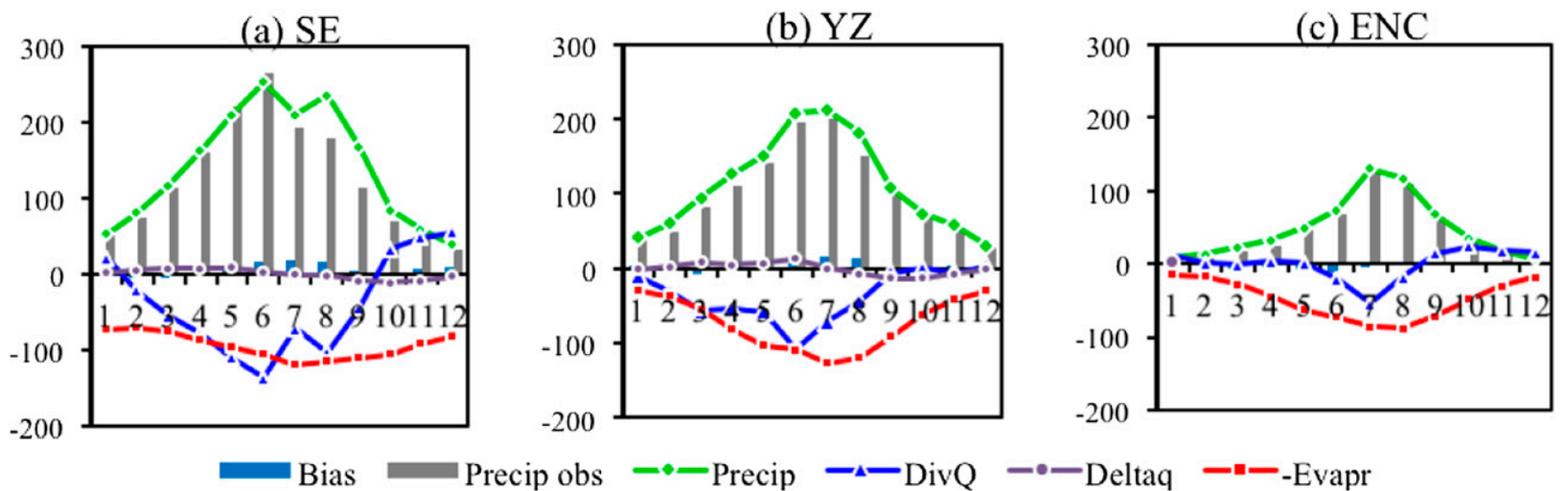

FIG. 11. The climatological annual cycle of the individual terms of the region-averaged moisture budget over (a) SE, (b) YZ, and (c) ENC. Individual terms include the precipitation (Precip, green), the evaporation (Evapr, red), the divergence of water vapor flux (DivQ, blue), the variation of total precipitable water (Deltaq, purple), and the bias (thick blue line) derived from ERA-Interim. The monthly variation of the precipitation from observation (Precip obs, gray) is also shown for comparison. 
(a) $\operatorname{Cor}(P$, Observed-P)

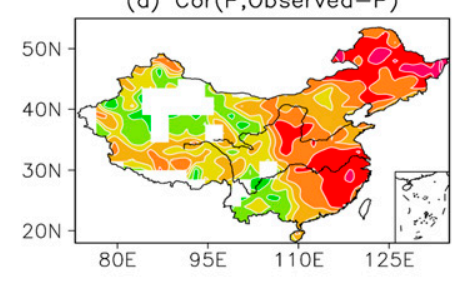

(b) $\operatorname{Cor}(-\operatorname{div} Q$, Observed-P)

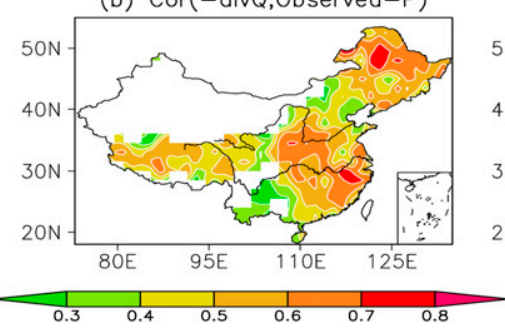

(c) $\operatorname{Cor}(E$, Observed-P)

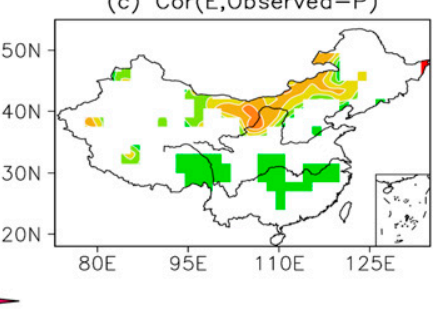

FIG. 12. Correlation between seasonal observed precipitation and (a) precipitation $(P)$, (b) moisture convergence $(-\operatorname{divQ})$, and (c) evaporation $(E)$ derived from ERA-Interim. Only the correlation coefficient significant at the $99 \%$ confidence level is shown.

mechanism (Yang et al. 2007; Xie et al. 2009; Yuan et al. 2012). Additionally, in contrast to Xie et al. (2009), who believed that local forcing can be ignored because the signal is weak on the seasonal scale, $\mathrm{Wu}$ et al. (2010) proposed that the local negative SSTA also contributes to the maintenance of the abnormal anticyclone in early $\operatorname{SUM}(+1)$ via the positive evaporation-wind-SST feedback (Wu et al. 2009, 2010). However, it is important to note that the impact of the local negative SSTA tends to lie near the center of the abnormal anticyclone, whereas that of the Indian Ocean warming tends to lie southwestward over the SCS. A comparison of the SSTA pattern response to CT and WP El Niño shows that the Indian Ocean basinwide warming during the mature winter to the decaying summer and the WNP cooling SSTA in the decaying June appear significantly only during CT El Niño, not during WP El Niño. That is also why the abnormal anticyclone, and thus the abnormal anticyclonic moisture circulation, persists over the WNP in the decaying summer of CT El Niño instead of WP El Niño.

Acknowledgments. This research is supported by the National Nature Science Foundation of China Project 41375096, 41175079, and 41275086, and the City University of Hong Kong Strategic Research Grants 7004004.

\section{REFERENCES}

Ashok, K., S. K. Behera, S. A. Rao, H. Weng, and T. Yamagata, 2007: El Niño Modoki and its possible teleconnection. J. Geophys. Res., 112, C11007, doi:10.1029/2006JC003798.

Chan, J. C. L., and W. Zhou, 2005: PDO, ENSO and the early summer monsoon rainfall over South China. Geophys. Res. Lett., 32, L08810, doi:10.1029/2004GL022015.

Chen, H., J. Sun, X. Chen, and W. Zhou, 2012: CGCM projections of heavy rainfall events in China. Int. J. Climatol., 32, 441-450, doi:10.1002/joc.2278.

Dee, D. P., and S. M. Uppala, 2008: Variational bias correction in ERA-Interim. ECMWF Tech. Memo. 575, 26 pp.

_ , and Coauthors, 2011: The ERA-Interim reanalysis: Configuration and performance of the data assimilation system. Quart. J. Roy. Meteor. Soc., 137, 553-597, doi:10.1002/qj.828.
Feng, J., and J. Li, 2011: Influence of El Niño Modoki on spring rainfall over South China. J. Geophys. Res., 116, D13102, doi:10.1029/2010JD015160.

_ - L. Wang, W. Chen, S. K. Fong, and K. C. Leong, 2010: Different impacts of two types of Pacific Ocean warming on Southeast Asian rainfall during boreal winter. J. Geophys. Res., 115, D24122, doi:10.1029/2010JD014761.

—, W. Chen, C.-Y. Tam, and W. Zhou, 2011: Different impacts of El Niño and El Niño Modoki on China rainfall in the decaying phases. Int. J. Climatol., 31, 2091-2101, doi:10.1002/ joc.2217.

Feng, L., and T. Zhou, 2012: Water vapor transport for summer precipitation over the Tibetan Plateau: Multidata set analysis. J. Geophys. Res., 117, D20114, doi:10.1029/2011JD017012.

Gu, W., C. Li, W. J. Li, W. Zhou, and J. C. L. Chan, 2009: Interdecadal unstationary relationship between NAO and east China's summer precipitation patterns. Geophys. Res. Lett., 36, L13702, doi:10.1029/2009GL038843.

Huang, R., and Y. Wu, 1989: The influence of ENSO on the summer climate change in China and its mechanisms. Adv. Atmos. Sci., 6, 21-32, doi:10.1007/BF02656915.

Kao, H.-Y., and J.-Y. Yu, 2009: Contrasting eastern-Pacific and central-Pacific types of ENSO. J. Climate, 22, 615-632, doi:10.1175/2008JCLI2309.1.

Kug, J.-S., F.-F. Jin, and S.-I. An, 2009: Two types of El Niño events: Cold tongue El Niño and warm pool El Niño. J. Climate, 22, 1499-1515, doi:10.1175/2008JCLI2624.1.

Larkin, N. K., and D. E. Harrison, 2005: Global seasonal temperature and precipitation anomalies during El Niño autumn and winter. Geophys. Res. Lett., 32, L16705, doi:10.1029/ 2005GL022860.

Li, C., W. Zhou, X. Jia, and X. Wang, 2006: Decadal/interdecadal variations of the ocean temperature and its impacts on the climate. Adv. Atmos. Sci., 23, 964-981, doi:10.1007/ s00376-006-0964-7.

Li, X., and W. Zhou, 2012: Quasi-4-yr coupling between El Niño-Southern Oscillation and water vapor transport over East Asia-WNP. J. Climate, 25, 5879-5891, doi:10.1175/ JCLI-D-11-00433.1.

- Z. Wen, and W. Zhou, 2011: Long-term change in summer water vapor transport over South China in recent decades. J. Meteor. Soc. Japan, 89A, 271-282, doi:10.2151/jmsj.2011-A17.

,,--- , and D. X. Wang, 2012: Atmospheric water vapor transport associated with two decadal rainfall shifts over East China. J. Meteor. Soc. Japan, 90, 587-602, doi:10.2151/ jmsj.2012-501.

Lin, R., T. Zhou, and Y. Qian, 2014: Evaluation of global monsoon precipitation changes based on five reanalysis datasets. J. Climate, 27, 1271-1289, doi:10.1175/JCLI-D-13-00215.1. 
Rayner, N. A., D. E. Parker, E. B. Horton, C. K. Folland, L. V. Alexander, D. P. Rowell, E. C. Kent, and A. Kaplan, 2003: Global analysis of sea surface temperature, sea ice, and night marine air temperature since the late nineteenth century. J. Geophys. Res., 108, 4407, doi:10.1029/2002JD002670.

Ren, H.-L., and F.-F. Jin, 2011: Niño indices for two types of ENSO. Geophys. Res. Lett., 38, L04704, doi:10.1029/2010GL046031.

Saji, N. H., B. N. Goswami, P. N. Vinayachandran, and T. Yamagata, 1999: A dipole mode in the tropical Indian Ocean. Nature, 401, 360-363.

Wallace, J. M., E. M. Rasmusson, T. P. Mitchell, V. E. Kousky, E. S. Sarachik, and H. Von Storch, 1998: On the structure and evolution of ENSO-related climate variability in the tropical Pacific: Lessons from TOGA. J. Geophys. Res., 103, 1424114259, doi:10.1029/97JC02905.

Wang, B., and Q. Zhang, 2002: Pacific-East Asian teleconnection. Part II: How the Philippine Sea anomalous anticyclone is established during El Niño development. J. Climate, 15, 3252-3265, doi:10.1175/1520-0442(2002)015<3252:PEATPI >2.0.CO;2.

-, R. Wu, and X. Fu, 2000: Pacific-East Asian teleconnection: How does ENSO affect East Asian climate? J. Climate, 13, 1517-1536, doi:10.1175/1520-0442(2000)013<1517: PEATHD $>2.0 . \mathrm{CO} ; 2$.

$\longrightarrow,-$, and T. Li, 2003: Atmosphere-warm ocean interaction and its impact on Asian-Australian monsoon variability. J. Climate, 16, 1195-1211, doi:10.1175/1520-0442(2003)16<1195: AOIAII $>2.0 . \mathrm{CO} ; 2$.

Wang, X., C. Li, and W. Zhou, 2006: Interdecadal variation of the relationship between Indian rainfall and SSTA modes in the Indian Ocean. Int. J. Climatol., 26, 595-606, doi:10.1002/ joc.1283.

, D. Wang, and W. Zhou, 2009: Decadal variability of twentieth-century El Niño and La Niña occurrence from observations and IPCC AR4 coupled models. Geophys. Res. Lett., 36, L11701, doi:10.1029/2009GL037929.

_- C. Wang, W. Zhou, D. Wang, and J. Song, 2011: Teleconnected influence of North Atlantic sea surface temperature on the El Niño onset. Climate Dyn., 37, 663-676, doi:10.1007/ s00382-010-0833-Z.

Weng, H., K. Ashok, S. K. Behera, S. A. Rao, and T. Yamagata, 2007: Impacts of recent El Niño Modoki on dry/wet conditions in the Pacific rim during boreal summer. Climate Dyn., 29, 113129, doi:10.1007/s00382-007-0234-0.

— - S. K. Behera, and T. Yamagata, 2009: Anomalous winter climate conditions in the Pacific rim during recent El Niño Modoki and El Niño events. Climate Dyn., 32, 663-674, doi:10.1007/s00382-008-0394-6.
Wu, B., T. Zhou, and T. Li, 2009: Seasonally evolving dominant interannual variability modes of East Asian climate. J. Climate, 22, 2992-3005, doi:10.1175/2008JCLI2710.1.

- T. Li, and T. Zhou, 2010: Relative contributions of the Indian Ocean and local SST anomalies to the maintenance of the western North Pacific anomalous anticyclone during the El Niño decaying summer. J. Climate, 23, 2974-2986, doi:10.1175/ 2010JCLI3300.1.

Xie, S.-P., K. Hu, J. Hafner, H. Tokinaga, Y. Du, G. Huang, and T. Sampe, 2009: Indian Ocean capacitor effect on Indowestern Pacific climate during the summer following El Niño. J. Climate, 22, 730-747, doi:10.1175/2008JCLI2544.1.

Yan, Z. W., J. J. Xia, C. Qian, and W. Zhou, 2011: Changes in seasonal cycle and extremes in China during the period 1960-2008. Adv. Atmos. Sci., 28, 269-283, doi:10.1007/ s00376-010-0006-3.

Yang, J., Q. Liu, S.-P. Xie, Z. Liu, and L. Wu, 2007: Impact of the Indian Ocean SST basin mode on the Asian summer monsoon. Geophys. Res. Lett., 34, L02708, doi:10.1029/2006GL028571.

Yang, S., K.-M. Lau, S.-H. Yoo, J. L. Kinter, K. Miyakoda, and C.-H. Ho, 2004: Upstream subtropical signals preceding the Asian summer monsoon circulation. J. Climate, 17, 4213-4229, doi:10.1175/JCLI3192.1.

Yeh, S. W., J.-S. Kug, B. Dewitte, M. H. Kwon, B. P. Kirtman, and F.-F. Jin, 2009: El Niño in a changing climate. Nature, 461, 511514, doi:10.1038/nature08316.

Yuan, Y., S. Yang, and Z. Zhang, 2012: Different evolutions of the Philippine Sea anticyclone between the eastern and central Pacific El Niño: Possible effects of Indian Ocean SST. J. Climate, 25, 7867-7883, doi:10.1175/JCLI-D-12-00004.1.

Zhang, R., A. Sumi, and M. Kimoto, 1996: Impact of El Niño on the East Asian monsoon: A diagnostic study of the 86/87 and 91/92 events. J. Meteor. Soc. Japan, 74, 49-62.

Zhang, W., F.-F. Jin, J. Li, and H.-L. Ren, 2011: Contrasting impacts of two-type El Niño over the western North Pacific during boreal autumn. J. Meteor. Soc. Japan, 89, 563-569, doi:10.2151/jmsj.2011-510.

Zhou, T.-J., and R.-C. Yu, 2005: Atmospheric water vapor transport associated with typical anomalous summer rainfall patterns in China. J. Geophys. Res., 110, D08104, doi:10.1029/ 2004JD005413.

Zhou, W., and J. C. L. Chan, 2007: ENSO and South China Sea summer monsoon onset. Int. J. Climatol., 27, 157-167, doi:10.1002/joc. 1380.

_ C. Y. Li, and J. C. L. Chan, 2006: The interdecadal variations of the summer monsoon rainfall over south China. Meteor. Atmos. Phys., 93, 165-175, doi:10.1007/s00703-006-0184-9. 